Souza, R.L.; Santos, E.O.; Baptista, M.L.C.; César, P.A.B. Percepção dos hóspedes do Refúgio Ecológico Pedra Afiada (SC): experiência e práticas ambientais. Revista Brasileira de Ecoturismo, São Paulo, v.9, n.1, fev/abr2016, pp.174-190.

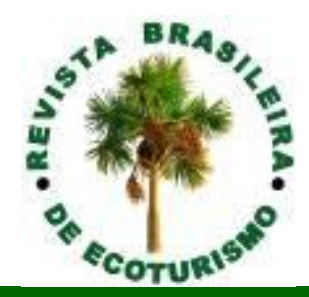

\title{
Percepção dos hóspedes do Refúgio Ecológico Pedra Afiada (SC): experiência e práticas ambientais
}

\section{Perception of guests Ecological Refuge Pedra Afiada (SC, Brazil): experience and environmental practices}

\author{
Rafael Lima de Souza, Eurico de Oliveira Santos, Maria Luiza Cardinale Baptista, \\ Pedro de Alcântara Bittencourt César
}

\begin{abstract}
RESUMO
O presente artigo apresenta uma análise da percepção dos hóspedes do Refúgio Ecológico Pedra Afiada, acerca da experiência vivenciada com as práticas ambientais adotadas pelo empreendimento. Pretendeu-se verificar a percepção dos consumidores da pousada, quanto à experiência vivenciada no meio natural e se as práticas adotadas pelo empreendimento são vistas como um diferencial, no momento da escolha do destino de férias. O referencial teórico associa pressupostos do Turismo no espaço rural com a subjetividade no turismo. Quanto à metodologia, trata-se de uma pesquisa exploratória com abordagem quali-quantitativa. Foram utilizadas duas técnicas de coletas de dados com os hóspedes do empreendimento, entrevista em profundidade e levantamento tipo survey, de opinião. Os dados recolhidos foram sistematizados em categorias de análise e confrontados com a bibliografia pertinente. A análise está alinhada aos temas emergentes da contemporaneidade, já que o ambientalismo ganhou força, nos anos pós-1990, tendo se transformado, a partir da Rio-92, em uma das principais preocupações mundiais. As empresas estão cada vez mais norteando suas ações, no sentido de diminuir o impacto causado ao meio ambiente e muitas práticas sustentáveis estão sendo criadas para que se atinja este objetivo. É o caso do Refúgio Ecológico Pedra Afiada, onde a preservação ambiental é um dos fatores mais relevantes para os diretores e colaboradores.
\end{abstract}

PALAVRAS-CHAVE: Turismo no Espaço Rural; Subjetividade no Turismo; Desenvolvimento Sustentável; Experiência de Consumo; Estilo de Vida; Percepção.

\section{ABSTRACT}

This paper presents an analysis of the perception of guests regarding service quality at the Refúgio Ecológico Pedra Afiada, especially regarding the experience they had with the environmental practices adopted by the enterprise (hotel). The goal of this study is to verify the impressions of the customers concerning the experience of living in an environment surrounded by nature and if the practices adopted by the enterprise are perceived as a distinguishing factor when choosing a holiday destination. The theoretical framework associates assumptions of Rural Tourism with subjectivity in tourism. As for the methodology, it is an exploratory research with a qualitative and quantitative approach. We used two techniques of data collection with the guests of the enterprise: in-depth interviews and an opinion-type of survey. The collected data were organized into categories of analysis and compared with the relevant literature. The analysis is in line with emerging contemporary issues, since environmentalism gained momentum in the post-1990 years, having been transformed since Rio-92 into a world concern. Companies are increasingly gearing their actions in order to reduce impact on the environment and carry out many sustainable practices to reach this goal. This is the case of the Ecological Refuge Sharp Stone, where environmental preservation is one of the relevant factors for management as well as for employees.

KEYWORDS: Rural Tourism; Subjectivity in Tourism; Sustainable Development; Consumption Experience; Lifestyle; Perception. 


\section{Introdução}

As preocupações com o desenvolvimento sustentável decorrem fundamentalmente dos resultados da Conferência das Nações Unidas sobre o Meio Ambiente e o Desenvolvimento, realizada no Rio de Janeiro, em junho de 1992, conhecida como Rio 92. O estabelecimento do conceito desenvolvimento sustentável tem como objetivo a utilização mais racional dos recursos e do ambiente. Para além desta vertente ambiental, há ainda a dimensão econômica e social, na exata medida em que a satisfação das necessidades das gerações atuais não cause degradação dos recursos e ponha em risco a satisfação das necessidades e os níveis de desenvolvimento das gerações futuras.

A gestão integrada e interdependente dos recursos, associada a uma perspectiva preventiva e de equidade intergeracional, constitui uma base de princípios consensuais que deviam ser transpostos para as políticas nacionais dos Estados. Uma série de contingências de diversas ordens, cuja análise transcende o objetivo deste estudo, no entanto, tem condicionado a sua efetiva implementação. A persistência de problemas ambientais e socioeconômicos, como o desmatamento, o número crescente de espécies ameaçadas de extinção, a poluição e a desigualdade social são o reflexo da falta de empenho e da defesa de outras prioridades, em detrimento do desenvolvimento sustentável, por parte dos governos.

As exigências do desenvolvimento sustentável são transversais a todos os setores da economia, incluindo o turismo, setor que vem sendo imbuído de diversas responsabilidades, no que diz respeito à preservação da natureza e da cultura. Só através de uma perspectiva de turismo sustentável, que defenda os recursos e as populações locais e proceda uma gestão racional dos valores, é possível diminuir os problemas decorrentes da massificação do turismo.

O Turismo no Espaço Rural (TER) é uma modalidade que, pelas suas características, contribui para a sustentabilidade não apenas do setor, mas do próprio desenvolvimento local/regional, em sentido mais amplo, devido ao conjunto de atividades que podem ser desenvolvidas. Primeiramente, porque o TER não é um turismo de massas e, assim, provoca menor impacto sobre a natureza. Por outro lado, a preservação da autenticidade em que se alicerça o TER exige uma gestão adequada em termos de conservação dos recursos (ambientais ou culturais), sem os quais uma localidade não pode almejar captar recursos. A sustentabilidade do TER manifesta-se por um conjunto articulado de ações, que passam pela recuperação do patrimônio arquitetônico, pela revitalização do patrimônio cultural (artesanato, gastronomia e tradições), pela preocupação em preservar a qualidade ambiental e a unidade paisagística. Por sua vez, o ecoturismo constitui o expoente máximo, em termos de sustentabilidade, pois, como explicitam Milheiro e Lima (2006), é uma atividade que privilegia o contato e a aprendizagem com a natureza, exercendo um pequeno impacto sobre os recursos ambientais e procurando trazer benefícios para as comunidades locais. Isso implica, necessariamente, na consideração dos sujeitos do lugar, de suas percepções e experiências.

Donaire (1999) afirma que a sustentabilidade do turismo deve se basear em sete princípios, que têm no TER uma maior expressão: a gestão das atividades, a integração, a abertura, o dimensionamento, a participação e a duração. A gestão abrange não somente os aspectos inerentes ao planejamento do território e a todas 
as políticas associadas à proteção ambiental e à identidade cultural, mas também às questões relacionadas com a gestão do produto, a sua comercialização, ao monitoramento, ao marketing e ao seu desenvolvimento futuro. No TER, a integração dos recursos deve ser uma realidade, pois é uma garantia da manutenção da identidade cultural e ambiental de um território, sem a qual o destino perde seu potencial atrativo. A abertura traduz-se na divulgação dos seus atributos, das suas especificidades locais, sem a qual as receitas dos públicos adeptos do TER não podem ser internalizadas nos espaços rurais. A sustentabilidade do turismo implica um adequado dimensionamento em termos espaciais e temporais.

A definição da capacidade de carga, sem por em causa a preservação dos recursos, bem como a eliminação da sazonalidade, procurando dinamizar atividades ao longo de todo o ano são medidas que beneficiam o desenvolvimento mais sustentável e a qualidade da oferta turística.

Fica claro, à medida que passa o tempo, que as organizações ligadas ao setor turístico que almejam se manter competitivas no mercado devem alinhar-se à nova perspectiva global e se tornar cada vez mais responsáveis com o meio ambiente. Isso trará, em longo prazo, grandes benefícios para toda a economia brasileira e mundial.

É exatamente nesta direção, de responsabilidade social e sustentabilidade, que tem se mostrado a atuação do Refúgio Ecológico Pedra Afiada, locus deste estudo. Situado no município de Praia Grande, no Estado de Santa Catarina, o empreendimento tem suas ações voltadas à preservação ambiental e desenvolve, com seus hóspedes, diversas práticas ambientais, a fim de promover a sua educação ambiental.

O objetivo do presente trabalho é analisar a percepção dos hóspedes do Refúgio Ecológico Pedra Afiada, acerca da experiência vivenciada em um local onde a preservação é o principal norteador das ações. Buscou-se entender se as práticas adotadas pelo empreendimento são vistas pelo consumidor como um diferencial, no momento da escolha do destino de férias.

\section{O Refúgio Ecológico Pedra Afiada e as práticas ambientais}

O Refúgio Ecológico Pedra Afiada, localizado no município de Praia Grande, no Estado de Santa Catarina, foi pensado e desenvolvido para qualificar a experiência de turismo ecológico na região dos Aparados da Serra. Está situado em uma região privilegiada, envolvido na cadeia de cânions, mais precisamente no Cânion Malacara, cercado pela Unidade de conservação do Parque Nacional da Serra Geral, conta com rica biodiversidade.

O Refúgio Ecológico Pedra Afiada trabalha com diversas práticas ambientais, como atividades que proporcionam a educação ambiental, realizadas com a escola municipal Bulcão Viana no projeto "Conhecer para preservar", uma iniciativa dos proprietários do empreendimento. Este projeto visa desenvolver a consciência ambiental em crianças do Ensino Fundamental e Médio, fazendo com que a ecologia e o respeito à natureza sejam despertados em casa e na escola.

Seguindo no âmbito social, a empresa criou um Alambique próprio, com o intuito de preservar a tradição regional de fabricação de cachaça, que se dissolveu 
com o tempo, por conta da entrada da indústria tabagista no município. Pequenos produtores locais são os fornecedores da matéria-prima que é envelhecida e aprimorada no Refúgio em Barris de Carvalho trazidos de Bento Gonçalves.

A empresa ainda faz parte de duas cooperativas locais, a Cooperativa de Eletricidade de Praia Grande (CEPRAG) e a Associação dos Colonos Ecologistas do Vale do Mampituba (ACEVAM), ambas com o intuito de fomentar a economia do município, gerando emprego e tornando-o mais próximo da realidade de questões da sustentabilidade. Mão de obra e matéria-prima para a implementação de novidades também são sempre locais.

Em relação aos fatores ambientais, pode-se ressaltar a utilização racional de energia, que se dá de várias formas. As construções foram feitas a partir de técnicas de bioconstrução. Assim, a luz solar é aproveitada quase na sua totalidade. São dez placas solares que servem para o aquecimento da água e para a iluminação externa. A água é proveniente de um rio que corta a propriedade e na construção foi tomado o máximo cuidado para que este não seja contaminado. O Instituto Brasileiro do Meio Ambiente e dos Recursos Naturais Renováveis (IBAMA) participou deste processo, orientando a construção de fossas ecológicas, filtros aeróbicos e anaeróbicos, e a distribuição de afluentes em forma de "espinha de peixe".

Os resíduos sólidos são todos separados. Plástico e metais são doados para a Associação dos Pais e Amigos dos Excepcionais (APAE), que vende e transforma o lixo em garantias financeiras. O papel é descartado na coleta seletiva do município e os dejetos orgânicos são colocados em uma composteira para virar adubo para a horta orgânica. Os restos de comida viram alimento para as galinhas.

Outra prática adotada pelo estabelecimento é a reutilização dos sabonetes biodegradáveis rejeitados pelos hóspedes. Em um hotel, sabe-se que os sabonetes devem ser novos a cada vez que se higieniza o banheiro. Com isso, hóspedes que ficam apenas uma diária não acabam o sabonete cedido pelo meio de hospedagem. Este sabonete é colocado em um recipiente grande com um pouco de água. Esta mistura faz com que eles se tornem uma pasta, que é utilizada para a limpeza das áreas de serviço, lavanderia e pátios externos.

Quanto à bioconstrução, as técnicas utilizadas no empreendimento são o adobe nas paredes externas, telhado verde com o intuito de regular a temperatura e excluir a necessidade de ar condicionado no verão, forro do telhado de embalagens de leite higienizadas e paredes internas de compensado reutilizado. A jacuzzi de uma das unidades foi feito com pedras do rio que corta a propriedade.

\section{Revisão de literatura}

\section{Turismo no Espaço Rural}

A gama de denominações destinadas às atividades turísticas que são desenvolvidas no espaço rural traz a necessidade de se utilizar a generalização "Turismo no Espaço Rural" (TER). Os autores Roque e Mendonça (1999, p.145) defendem a utilização deste termo genérico, para definir "[...] toda maneira turística de visitar e conhecer o ambiente rural, enquanto se resgata e valoriza a cultura regional". 
Já Oxinalde (1994 apud SILVA; VILARINHO; DALE, 2000, p.16) considera sinônimos os termos Turismo Rural e Turismo no Espaço Rural, quando diz que "turismo rural engloba modalidades de turismo, que não se excluem e que se complementam, de forma tal que o turismo no espaço rural é a soma do ecoturismo e turismo verde, turismo cultural, turismo espontâneo, agroturismo e turismo de aventura".

Para Zimmermman (2000, p.130):

As atividades turísticas nos meios naturais têm recebido uma proliferação de termos, que fazem referências ao turismo rural: turismo de interior, turismo verde, turismo diferente, turismo alternativo, turismo rural e ecológico e por aí a fora. Evidentemente, cada atividade possui características próprias, que, dependendo das características geomorfológicas do espaço podem estar juntas, sob a denominação genérica de turismo rural.

Ainda, no Caderno Diretrizes para o Desenvolvimento do Turismo Rural:

Entende-se Turismo no Espaço Rural como um recorte geográfico, [...] as muitas práticas turísticas que ocorrem no espaço rural não são, necessariamente, Turismo Rural, e sim atividades de lazer, esportivas ou ócio de citadinos que ocorrem alheias ao meio que estão inseridas. (BRASIL, 2003, p.7).

Pode-se dizer ainda que, para além da proliferação de todos estes termos utilizados, o próprio termo "turismo rural" pode ser analisado sob uma nova ótica. De acordo com Froehlich e Rodrigues (2000), na atualidade fica muito complicado que as dualidades rural/urbano, tradicional/moderno e cidade/campo sejam levadas como verdade. Isso porque, segundo os autores, houve um "transbordamento" do que se considerava urbano para o rural, fazendo com que as características de ambos se sobrepusessem. Corroboram com esta construção Del Grossi \& Silva (2002), ao analisarem a crescente urbanização do meio rural, processo denominado "Novo Rural", onde, "[...] um conjunto de atividades não agrícolas, ligadas à moradia, ao lazer e a várias atividades industriais e de prestação de serviços são inseridas no espaço antes destinado exclusivamente à produção agrícola" (DEL GROSSI; SILVA, 2002, p.5).

\section{Turismo sustentável e preocupação ambiental}

Nas últimas décadas, o turismo no Brasil caracterizou-se pela maneira desordenada como vem se expandindo. Devido à grande extensão territorial do país, o turismo representa uma grande parcela de movimento em sua economia.

Segundo Ferrão et al. (1992 apud RUSCHMAN, 2002), a demanda crescente dos turistas por viagens que proporcionam o contato direto com a natureza coloca - Brasil em posição privilegiada, como destinação para a demanda do turismo ecológico e de aventura. Isso ocorre tanto em nível nacional quanto internacional, em função de seus inúmeros recursos naturais, dentre os quais se destacam os ecossistemas que são encontrados apenas aqui. 
Na definição da Organização Mundial do Turismo (OMT, 2001), o turismo sustentável corresponde a um modelo de desenvolvimento econômico projetado para melhorar a qualidade de vida da população que vive e trabalha no local turístico, manter a qualidade do meio ambiente da qual depende a população e os visitantes, aumentar os níveis de rentabilidade econômica da atividade turística para os residentes locais, assegurar a lucratividade do empreendimento e melhorar a qualidade da experiência para o visitante.

Para Barbieri (2004), a solução dos problemas ambientais ou sua minimização exige uma nova atitude dos empresários e administradores, que devem passar a considerar o meio ambiente em suas decisões e adotar concepções administrativas e tecnológicas que contribuam para ampliar a capacidade de suporte do planeta.

$\mathrm{Na}$ definição da Organização Mundial do Turismo (OMT, 2001), o turismo sustentável corresponde a um modelo de desenvolvimento econômico, projetado para melhorar a qualidade de vida da população que vive e trabalha no local turístico; manter a qualidade do meio ambiente, da qual depende a população e os visitantes; aumentar os níveis de rentabilidade econômica da atividade turística para os residentes locais; assegurar a lucratividade do empreendimento; e melhorar a qualidade da experiência para o visitante.

O que está em questão no desenvolvimento do turismo sustentável, no entanto, não são apenas definições políticas, mas sim medidas mitigadoras a serem tomadas para remediar ou diminuir possíveis impactos ambientais que 0 turismo possa causar.

Segundo o Relatório Brundtland, desenvolvimento sustentável:

É aquele que harmoniza o imperativo do crescimento econômico com a promoção da equidade social e preservação do patrimônio natural, garantindo assim que as necessidades das atuais gerações sejam atendidas sem comprometer 0 atendimento das necessidades das gerações futuras (NOSSO FUTURO COMUM, 2012, texto digital).

No Brasil, a preocupação com a preservação ambiental é recente. Teve seu início na década de 1970. Para Pelegrini Filho (2000, p. 28), "[...] nessa década começaram também as pressões internacionais pela preservação do meio ambiente, ao que o governo federal replicou com o argumento de que a pobreza é a maior poluição, e que a orientação oficial era acabar com essa chaga".

Como resultado de inúmeros incentivos governamentais a projetos agropecuários, surgiram, no Brasil, diversas campanhas ambientais que geraram um debate sobre meio ambiente. Pelegrini Filho (2000, p.28) diz que:

$\mathrm{Na}$ década de 1980/90, o debate de assuntos relacionados à ecologia provocou uma considerável conscientização dos problemas ambientais, com importante papel cumprido por órgãos oficias de comunicação, que chegam a reservar grandes espaços e tempos para notícias, entrevistas, mesas-redondas e semelhantes, além de matérias e programas importados. 
Nas últimas décadas do século passado, o setor público e privado, empresas e algumas organizações não governamentais iniciaram a destinação de parte dos seus recursos a ações de prevenção e de minimização dos impactos ambientais. Sendo eles os atores que detêm o capital, chegaram à conclusão de que estavam levando o planeta a uma situação doentia e irreparável, principalmente com aceleração do processo de efeito estufa.

De acordo com Longenecker (1981), a empresa deve reconhecer que sua responsabilidade para com a sociedade, o meio ambiente e o público em geral vai além de suas responsabilidades com os seus clientes. Nesse sentido, cabe aos administradores desenvolver um aguçado senso de responsabilidade social, haja vista que suas decisões extrapolam as considerações meramente econômicas. Essa percepção é importante, pois, somente com um grande senso de responsabilidade social, as empresas se sensibilizam para questões ambientais.

Uma empresa hoteleira, elemento essencial da infraestrutura turística, constitui um dos suportes básicos para o desenvolvimento do turismo (BENI, 1998). Dessa forma, uma empresa hoteleira, assim como qualquer outra, necessita de uma administração adequada, a fim de satisfazer tais diferenças e gerar resultados organizacionais para a sobrevivência do hotel. Entre os resultados que as empresas devem buscar, estão as metas de gestão ambiental, já que hoje nenhuma empresa consegue sobreviver no mercado sem este olhar sob a preservação do meio ambiente.

Para Barrow (1999, p.18), as metas da gestão ambiental incluem os seguintes tópicos: a) prevenção e resolução dos problemas ambientais; b) estabelecimento de limites; c) estabelecimentos e manutenção de instituições que efetivamente apoiam a pesquisa; d) o monitoramento e o gerenciamento do meio ambiente; e) sustentação e, se possível, ampliação dos recursos naturais existentes; f) ampliação da qualidade de vida e, g) identificação de novas tecnologias ou políticas que sejam úteis.

Sabe-se que a gestão ambiental pode auxiliar uma companhia a gerir, a medir e a melhorar os cuidados com o meio ambiente, que são voluntários e obrigatórios. Além disso, pode ajudar essas mesmas empresas a realizarem uma mudança cultural, à medida que práticas ambientais forem sendo incorporadas nas operações diárias e se tornarem parte do cotidiano do negócio.

A gestão Ambiental é entendida como decorrente de processos adaptativos e contínuos, através dos quais as organizações definem e redefinem seus objetivos e metas, relacionados à proteção do ambiente, à saúde de seus empregados, bem como de clientes e da comunidade. Além disso, implica em selecionar estratégias e meios para atingir estes objetivos num tempo determinado através de constante avaliação de sua interação com o meio ambiente externo (ANDRADE, 2000).

As organizações que já estão praticando a gestão ambiental (ou mesmo as empresas que estão passando pelo processo de adequação de diretrizes para estabelecer a maneira com que vão levar o tema) devem ter bem claras as dificuldades e os pontos mais importantes para se efetivar um SGA. Isso é importante, independente do quanto essas organizações estão envolvidas, diretamente, com questões relacionadas ao ambiente natural.

$\mathrm{Na}$ hotelaria, também se verifica que pequenos, médios e grandes meios de hospedagens estão direcionando suas ações, a fim de diminuir o impacto no meio 
ambiente em que estão localizados, bem como suas repercussões no macro ambiente.

Como finalidade da gestão ambiental para meios de hospedagem, pode-se observar o encurtamento dos processos e a minimização do impacto que cada um deles pode causar ao meio ambiente. A lucratividade do empreendimento aumenta ao passo que os custos operacionais vão diminuindo, em uma variável contrária à aplicação da eficiência ecológica.

Um exemplo que deixa mais clara esta relação são os procedimentos corretos de gerenciamento dos produtos químicos, que, diversas vezes, conseguem reduzir os custos operacionais dos tratamentos de esgoto e afluentes, melhorando de maneira muito significativa a qualidade da água.

A afinidade do homem com o seu meio ambiente revela prontamente a questão de como ele arquiteta a sua condição de vida, o que é reflexo das alternativas econômicas escolhidas. Vale ressaltar que a qualidade ambiental interfere diretamente na qualidade de vida do ser humano e essas duas variáveis estão também relacionadas com a questão econômica.

As implicações ambientais atribuídas à ação do homem vêm tomando proporções apavorantes nas mais variadas partes do planeta. Nos países desenvolvidos e nos em desenvolvimento, o crescimento demográfico e o acúmulo de pessoas têm trazido danos irreparáveis. Grande parte da destruição, verificada em países em desenvolvimento, se dá para satisfazer à demanda de insumos dos países desenvolvidos. O efeito disso é o que vem acontecendo ao longo dos últimos anos, numa busca desenfreada de medidas e soluções, os governos sendo pressionados pela comunidade internacional, através de encontros, congressos e tratados, a optarem e incentivarem a adoção de ações efetivas em prol do meio ambiente.

Esse problema pode ser facilmente verificado nos meios de hospedagem, já que a legislação nacional, até 2002, não exigia da maioria dos empreendimentos hoteleiros a implantação de qualquer tipo de Sistema de Gestão Ambiental. Essa situação permitia que qualquer empresário tivesse olhos apenas para a gestão de negócios, não se importando muito com o meio ambiente. Isto começou a ser revertido quando os presidentes da $\mathrm{ABIH}$ e da Embratur aprovaram um novo sistema de qualificação de hotéis, no qual só se atingiria um nível de excelência, se também demonstrassem preocupação e desenvolvessem ações para diminuir os impactos ambientais gerados pelas atividades do estabelecimento (GONÇALVES, 2004).

Devido a esse novo cenário econômico, em que também a população civil exige cada vez mais atitudes ecologicamente corretas das empresas e governo alertando-os da poluição industrial em nível federal, possibilidade de cidades estabelecerem controles de qualidade ambientais independentes, estabelecimento de penalidades para agravantes e/ou descumprimento ambiental, benefícios fiscais, entre outros (ALMEIDA, 2004).

Sendo assim, pode-se considerar que as questões de sustentabilidade e gestão ambiental, em meios de hospedagem, ainda estão se adaptando a estilos gerenciais, mercado, localização física, concorrência, ente outros, pois, nesse novo contexto político, gerencial e mercadológico, a imagem está cada vez mais vinculada à ideia de resultados efetivos e a oferta de bens e serviços, que 
possibilitem a melhoria da qualidade de vida. Assim sendo, o gerenciamento em busca da qualidade total ou da melhoria contínua na gestão empresarial está associado a novos estilos de gerenciar e promover mudanças, com base no combate ao desperdício e não atendimento às expectativas dos clientes (SCHENINI, 2005).

Se o futuro das presentes e próximas gerações depende da real compreensão da inter-relação que há entre o ser humano e o meio ambiente, a maioria dos problemas ambientais tem suas raízes em fatores sociais, econômicos, políticos, culturais e éticos.

\section{Experiência de consumo e estilo de vida}

Não há como analisar a percepção de um cliente acerca de um determinado tema, se não falarmos sobre experiência de consumo. Segundo Hopkinson e Pujari (1999), a "experiência" tem ganhado popularidade na pesquisa de Marketing. A relevância que a experiência assume na prestação de serviços vem crescendo juntamente com o crescimento do número publicações que tratam de como as pessoas consomem a experiência e também o porquê optam por fazê-lo.

Pine e Gilmore (2000, p. 18) tratam experiência como sendo, "eventos memoráveis que envolvem os consumidores de um modo pessoal". A experiência de consumo é vista como algo singular, não havendo a possibilidade de duas pessoas terem a mesma experiência, tendo em vista a interação única entre cada pessoa e um determinado evento, mostra Pine e Gilmore (apud ZILLES, 2006).

Ao tentar verificar a percepção de um cliente, deve-se levar em conta, segundo Caru e Cova (2008), que a experiência de consumo provoca sensações e sentimentos que vão muito além da satisfação das necessidades básicas de um indivíduo, impactando diretamente na busca da própria identidade.

Sendo assim, Segundo Schmitt (2002), a experiência de consumo pode ser dividida em cinco tipos: sensorial, física, cognitiva, identificação e emocional. Para que se possa visualizar melhor cada tipo proposto, faz-se necessário uma explanação acerca dos mesmos segundo o próprio autor.

Quanto às experiências sensoriais, pode-se dizer que tratam de incorporar os cinco sentidos humanos, tato, visão, olfato, paladar e audição. Esta experiência está diretamente ligada aos sons, cheiros, gostos, formas e texturas. Pode-se dizer que este tipo está relacionado ao sentido da beleza e da excitação de quem consome. Já as experiências emocionais falam em estímulos sentimentais. Podem gerar, muitas vezes, sentimentos contraditórios como amor e ódio, remetem ao envolvimento com agentes, eventos e objetos.

As experiências de identificação tratam de fazer a conexão entre o consumidor e os contextos sociais e culturais atribuídos a uma marca, ajudando na criação de uma identidade social para este consumidor.

Ainda tratando dos tipos de experiência, as físicas apontam para um despertar de padrões alternativos ao comportamento e estilo de vida, a fim de proporcionar uma melhora na interação social de quem consome determinado produto ou serviço. Por último, a experiência cognitiva, remete a pensamentos associativos e direcionais, que podem ou não provocar perplexidade ou apenas surpresa à pessoa que vivencia determinada situação. 
As experiências são, portanto, resultado da incidência de diferentes vivências em determinadas situações. São os estímulos criados para os sentidos humanos, para a mente e para a formulação dos sentimentos. Perante isso, faz-se indispensável que se conceitue sensação e percepção. A primeira, segundo Schiffman e Kanuk (1997), se refere à resposta direta e imediata de um órgão dos sentidos humanos diante de um estímulo. A segunda, por sua vez, se refere à forma como utilizamos os sentidos para perceber o mundo. Estes estímulos podem ser captados abaixo do nível consciente.

Pine e Gilmore (2000) afirmam que as sensações que formam a percepção são a quarta atividade econômica, sendo uma evolução natural da antiga concepção de commodity, bens e serviços. Os autores discorrem que as sensações são o mais perfeito elemento para acrescentar valor a um determinado bem ou serviço, isso porque as commodities são fungíveis, os bens, são tangíveis e os serviços, intangíveis. Restam, apenas, as sensações, que são envolvidas de emoções, de contato físico, intelectual e até mesmo espiritual.

Comumente, a aquisição de um bem ou o uso de um serviço é orientada por peculiaridades do ambiente, contato físico e outros elementos, sendo que as experiências continuam, mesmo após o consumo. A importância da emoção continua na memória das pessoas, mesmo que a sensação não seja palpável, pois as pessoas atribuem valor à atividade.

As experiências não são espontâneas. Conforme Schimitt (2002), os profissionais do marketing normalmente tendem a prover aos consumidores tais estímulos que resultam em uma experiência para o cliente. Para isso, faz-se necessário que se conheça muito bem o consumidor de determinado produto ou serviço, traçando o perfil e o seu estilo de vida do cliente.

Estilo de vida é a forma como uma pessoa ou até mesmo um grupo de pessoas toma suas decisões e se comporta no cotidiano, na rotina, nos padrões de consumo, ou ainda a maneira como estas pessoas se adaptam ao dia a dia. Segundo Nahas (2006), é o conjunto de ações cotidianas que refletem nas atitudes e valores das pessoas. O estilo de vida, por sua vez, pode mudar ao longo dos anos, mas isso só acontecerá se a pessoa conscientemente enxergar algum motivo relevante para incluir ou excluir valores ou atitudes, assim como, se sentir capaz de realizar as mudanças pretendidas (NAHAS, 2006).

\section{Metodologia}

Para a elaboração de uma pesquisa, é necessário escolher um método. Segundo Köche (1997), método é a definição de passos gerais aplicados na investigação científica. Para a realização deste estudo, cujo objetivo principal foi a análise da percepção dos hóspedes do Refúgio Ecológico Pedra Afiada, acerca da experiência vivenciada com as práticas ambientais adotadas pelo empreendimento, foi feita uma pesquisa exploratória com abordagem qualitativa e quantitativa.

A pesquisa exploratória pode ser definida como o primeiro passo de todo o trabalho científico. Permite que se busquem informações acerca de um tema sobre o qual não se possui conhecimento acumulado e sistematizado. Para Malhotra (2006), é partir desse momento que o pesquisador consegue juntar elementos e torná-los mais úteis, de tal forma a definir prioridades a serem pesquisadas. 
Já a combinação das duas abordagens, qualitativa e quantitativa, se deu por tonar a análise e os resultados mais fidedignos e profundos. Davies (2003) corrobora com a afirmação, defendendo a combinação dos dois métodos, pois considera que a complementaridade entre as duas abordagens é importante para o aprofundamento do conhecimento científico em turismo.

As técnicas de coleta de dados utilizadas foram a entrevista em profundidade e o levantamento, tipo survey, de opinião. Segundo Malhotra (2006, p.163), este tipo de entrevista "serve para descobrir motivações, crenças, atitudes e sensações subjacentes a um tópico" e, de acordo com Dencker (1998), o levantamento evidencia a distribuição estatística das respostas a um questionário estruturado, aplicado a uma amostra da população, possibilitando avaliar a percepção dos turistas quanto à experiência vivenciada.

A partir daí foi elaborado um roteiro de questões do tipo abertas, fechadas e de múltipla escolha, utilizando-se em algumas questões a escala de Linkert 5 graus. Segundo Dencker (1998, p.183), "esta escala quantifica a atitude dos indivíduos baseada em uma ordem de importância numérica qualificativa", de maneira a extrair do pesquisado sua percepção a respeito do objeto de estudo.

A amostragem foi de 15 (quinze) hóspedes do Refúgio Ecológico Pedra Afiada, entrevistados no período entre os meses julho a outubro de 2013, sendo que a seleção dos mesmos se deu de maneira probabilística do tipo aleatória simples. Para garantir a veracidade aos resultados, foi utilizado um aparelho gravador de voz, que auxiliou na análise dos dados obtidos.

De acordo com Bardin (1977), os dados devem ser analisados a partir de uma análise de conteúdo por categorias, permitindo a classificação dos elementos significativos para o estudo. Dessa forma, foi realizada a transcrição do conteúdo e a categorização dos dados, com o objetivo de encontrar padrões e reproduzir explicações.

Foram cumpridas as seguintes etapas práticas, determinadas por Silverman (2009), a) documentação e transcrição das entrevistas em profundidade com hóspedes do REPA; b) pré-análise dos dados coletados; c) codificação e categorização do dados, por meio da seleção das informações relevantes e categorização dos dados de acordo com os construtos a serem estudados; d) interpretação dos dados por meio da análise dos dados extraídos da etapa anterior e e) elaboração do relatório de resultados, através da explicitação de evidências e consolidação de resultados comparativos.

\section{Resultados}

Inicialmente verificou-se, através de perguntas fechadas, o perfil dos hóspedes entrevistados. Neste momento se estabeleceu, de acordo com a Figura 1 , que $60 \%$ da amostra eram mulheres e $40 \%$ homens. Em relação à idade, podese perceber, na Figura 2, que 20\% dos entrevistados possuíam entre 18 e 25 anos, $46,6 \%$ se encontravam na faixa etária que vai de 26 a 35 anos e $33,3 \%$ tinham entre 36 e 50 anos de idade. Destes entrevistados, 33,3\% eram solteiros, 46,6\% casados, $13,3 \%$ separados e $6,6 \%$ viúvos. Fica evidente que os números se concentram em uma população relativamente jovem que exclui a terceira idade. 


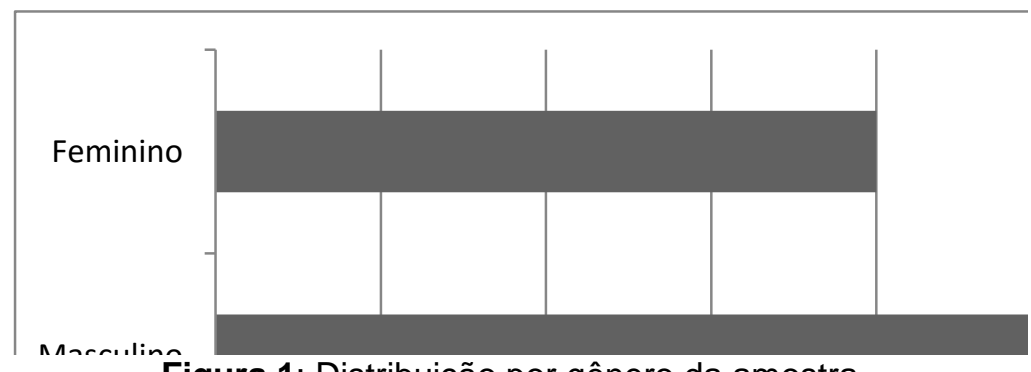

Figura 1: Distribuição por gênero da amostra.

Figure 1: Distribution by gender of the sample.

Fonte: dados da pesquisa.

Source: research data.

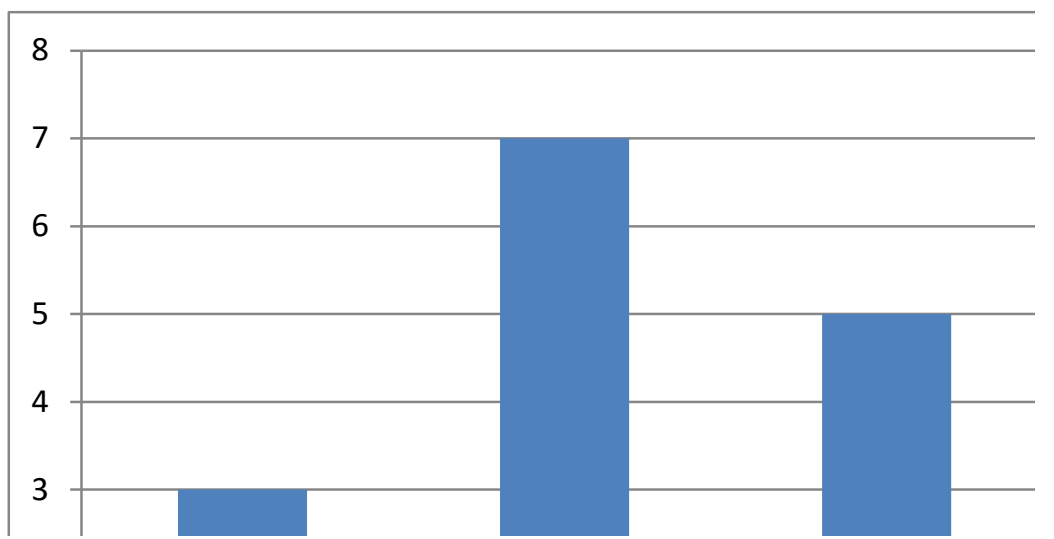

Figura 2: Distribuição por faixa etária da amostra.

Figure 2: Distribution by age of the samples.

Fonte: dados da pesquisa.

Source: research data.

Quanto ao nível de escolaridade, $80 \%$ possuíam nível superior completo e os outros $20 \%$ estavam cursando graduações. A procedência deste visitante em sua totalidade, ou seja, $100 \%$ era urbana. Estes dados mostram que os visitantes do local são pessoas com conhecimento avançado em relação a questões locais e globais, que sabem a respeito da necessidade de se preservar o meio ambiente e incluir a população local nos benefícios trazidos pelo turismo.

Quando perguntados sobre como avaliavam a relação com a natureza e com as práticas ambientais desenvolvidas no REPA, $60 \%$ avaliou a experiência como excelente, $33,3 \%$ avaliou como bom e apenas 6,6\% considerou regular, evidenciando que a interação entre hóspede e meio ambiente se dá de maneira muito satisfatória na visão dos clientes.

Em relação à qualidade da experiência como um todo, considerando a hospedagem, o serviço e o entretenimento junto à natureza, $86,6 \%$ dos hóspedes julgaram excelente e 13,3\% consideraram bom, corroborando assim com a afirmação anteriormente feita.

Através desta pesquisa, pôde-se verificar que os frequentadores do empreendimento possuem uma visão fragmentada do termo sustentabilidade e apenas conseguem conectá-lo à sua dimensão ambiental. É o que fica evidenciado nos extratos retirados das entrevistas, "Acho que sustentabilidade é tu fazer ou ter uma ação que prejudique o meio ambiente da menor maneira possível" (Entrevistado 1). 
"Sustentabilidade para mim é um termo super atual, se refere ao fato de termos que alinhar nossas necessidades ao que o planeta tem para nos oferecer. Acredito que seja um termo utilizado para conscientizar que devemos preservar o planeta para garantirmos as futuras gerações" (Entrevistado 8).

Segundo Jacobi (1997, p.196) "[...] a noção de sustentabilidade implica em uma inter-relação necessária de justiça social, qualidade de vida, equilíbrio ambiental e a ruptura com o atual padrão de desenvolvimento".

Apenas os consumidores que possuem alguma atividade que possa ser relacionada ao termo conseguem visualizar a inter-relação dos três pilares da sustentabilidade, como se pode observar no seguinte trecho.

"A sustentabilidade para mim é um tripé que deve ser respeitado por todos os seres humanos. Para alcançarmos o desenvolvimento sustentável temos que estar suscetíveis a mudanças no setor econômico, ambiental e sociocultural" (Entrevistado 12).

Notou-se também, que, após a experiência, muitos hóspedes passam a se interessar mais pelo assunto e se percebeu que a identificação dos clientes com a missão da empresa acaba por se tornar uma maneira de disseminar a educação ambiental. Brown (2009) mostra que, frente a todas as constantes mudanças, tanto sociais como ambientais, é preciso que o mundo todo se mobilize, a fim de tentar viabilizar a manutenção da vida na terra.

Podemos verificar também que os consumidores do REPA possuem um estilo de vida semelhante, que, segundo Nahas (2006), é "o conjunto de ações cotidianas que reflete as atitudes e valores das pessoas". Todos os hóspedes são oriundos de grandes cidades, o que realça a ideia de que o investimento do empreendimento tem que estar voltado para a criação de estímulos que propiciem uma melhor experiência para este público-alvo. Entre eles, pode-se notar a falta de tempo como fator comum, juntamente com a característica de possuírem uma rotina muito agitada, de acordo com uma das entrevistas:

"Minha rotina é muito agitada e não tenho muito tempo para executar muitas coisas em relação à ideia de preservação. Como sou arquiteta, no meu trabalho, sim, me preocupo muito com o tema. Afinal, hoje em dia todos os segmentos de mercado estão se preocupando muito com a natureza. Posso dizer que é "Cult" se preocupar com a ecoeficiência" (Entrevistado 8).

Estes fatores influenciam muito na percepção de qualidade expressa pelos clientes. Ao entrarem em contato com a natureza e saírem do turbilhão da cidade, eles ficam muito satisfeitos com a experiência, agregando-lhe muito valor.

Ficou evidente que os hóspedes do Refúgio Ecológico, antes do primeiro contato com o local, não tem conhecimento de todo o trabalho de preservação realizado pela empresa, nem mesmo que este é o foco e a missão do empreendimento. Quando vivenciam a experiência e entram em contato com a 
atitude do empreendimento, passam a considerá-la um diferencial, conforme um dos entrevistados: "Para ser sincero, para mim não tinha sido um diferencial na hora de escolher, mas chegando aqui acabou se tornando o principal diferencial" (Entrevistado 12).

Antes disso, o único diferencial citado é a beleza natural e exuberante do local. Isso faz com que se proponha uma mudança no contato com o cliente. Este deve saber dos diferenciais oferecidos pela empresa no momento da escolha e não apenas na chegada ao local.

Dessa forma, percebe-se que as práticas sustentáveis realizadas no Refúgio, não são, portanto, um diferencial no momento de escolha do destino de férias. Elas passam a tomar este caráter após a experiência, após a vivência in loco, de tais sentimentos e novas percepções.

Verificamos que as decisões dos proprietários, como a falta de televisão e internet nas unidades habitacionais, a fim de restringir ao mínimo necessário o tempo nos quartos e promover uma maior interação com a natureza e com as práticas sustentáveis, não são bem vistas pelos consumidores. Um dos entrevistados afirma que: "Pontos negativos só vi um. Acho que não precisa se isolar de tudo o que está acontecendo no mundo, para se conectar com a natureza" (Entrevistado 8). Segundo Bauman (2009, p.166), ninguém mais pode se dar o direito de estar "temporariamente fora de serviço", todos vivem em estado constante de emergência. Ao contrário do que imaginávamos, os clientes reclamam da falta de opções de lazer à noite.

Outro fator constatado é que a utilização de veículos automotores em passeios é vista como "fora da proposta da pousada" e poderia ser extinta, segundo este hóspede,

"Já os aspectos que não me agradaram e que eu acredito que desvalorizam um pouco a ideia de preservação é um dos passeios que é feito com quadricículos com motor, que polui, faz barulho e acaba não condizendo com o que eles propõem" (Entrevistado 3)

Foi verificado, nas entrevistas, que falta uma melhor comunicação entre os atores do cenário estudado. Os consumidores devem ter acesso, antes de decidirem o local de férias, às informações relacionadas às práticas ambientais e ao trabalho de preservação realizado no Refúgio Ecológico Pedra Afiada. Assim o principal diferencial do estabelecimento vai ser visto e poderá ser pensado pelo consumidor anteriormente à compra.

\section{Considerações finais}

Este estudo teve como objetivo verificar a percepção dos hóspedes do Refúgio acerca das práticas sustentáveis adotadas pelo empreendimento, identificando se estas práticas realmente são um diferencial na hora da escolha do destino de férias.

Através da análise feita, pode-se concluir que os clientes do REPA não chegam até o empreendimento bem informados do engajamento que a empresa tem em relação ao meio ambiente em que está inserida. Em sua totalidade, a amostra de frequentadores do meio de hospedagem foi de pessoas oriundas de 
grandes centros urbanos, com alto nível de escolaridade, mas com um entendimento fragmentado em relação ao termo sustentabilidade.

Através das respostas obtidas, foi verificado que as práticas sustentáveis não são um diferencial num primeiro momento, na escolha do destino. Este diferencial só é percebido pelo cliente no momento em que este vivencia a experiência.

Cabe salientar, ainda, que as constatações deste trabalho devem ser relativizadas, considerando-se o fato de os entrevistados terem expressado sua percepção em uma determinada situação induzida, onde possivelmente tenham administrado suas respostas, a fim de vincular o tema da preservação ambiental e práticas favoráveis ao meio ambiente às suas vidas. Sabe-se que o tema vem sendo tratado com seriedade e as pessoas estão com discursos mais elaborados do que executando atitudes efetivas.

\section{Referências bibliográficas}

ALMEIDA, J.R.; MELLO, C.S; CAVALCANTI, Y. Gestão ambiental: planejamento, avaliação, implantação, operação e verificação. 2. ed. Rio de Janeiro: Tex, 2004.

ANDRADE, R.O.B.; TASCHIZANA, T; CARVALHO, B.. Gestão ambiental: enfoque estratégico aplicado ao desenvolvimento. 2. ed. São Paulo: Makron Books, 2002.

BARBIERI, J.C. Gestão ambiental empresarial: conceitos, modelos e instrumentos. São Paulo: Saraiva, 2004.

BARROW, C.J. Environmental management: principles and practice. New York. Routledge, 1999.

BENI, M.C. Análise Estrutural do Turismo.5 ed. São Paulo: Editora SENAC. São Paulo, 1998.

BRASIL. Ministério do Turismo. Plano Nacional do Turismo: Diretrizes, Metas e Programas. 2003 - 2007. Brasília, 29/04/2003.

BROWN, L.R. Ecoeconomia. La constucció d'uma economia per a La terra. Local: Centre UNESCO de Catalunya, 2009.

CARU, A.; COVA, B. Small versus big stories in framing consumption experiences. Qualitative market research. An international journal, v.11, n.2, p.166-176, 2008.

CROSBY, A.; MOREDA, A. Desarollo y gestión del turismo em áreas rurales y naturales. Madri: Centro Europeo de Formación Ambiental y Turística. 1996.

DAVIES, B. (2003). The role of quantitative and qualitative research in industrial studies of tourism. International Journal of Tourism Research. Vol. 5, N. 2, p. 97111.

DEL GROSSI, M.E.; SILVA, J.G. O novo rural: uma abordagem ilustrada. Londrina, PR: IAPAR, v.1, 2002.

DENCKER, A.F.M. Métodos e Técnicas de Pesquisa em Turismo. São Paulo, SP: Futura, 1998.

DONAIRE, D. Gestão ambiental nas empresas. São Paulo: Atlas, 1999.

FROELICH, José M.; RODRIGUES, Ivone da S. A atividade turística e espaço agrário: considerações exploratórias sobre o município de Restinga Seca (RS). In: ALMEIDA, 
Joaquim A.; FROELICH, José M.; RIEDL, Mario (orgs). Turismo rural e desenvolvimento sustentável. Campinas, SP: Papirus, 2000.(Coleção Turismo).

GONÇALVES, L.C. Gestão ambiental em meios de hospedagem. São Paulo: Aleph, 2004.

HOPKINSON, G.C.; PUJARI, D. A factor analytic of the sources of meaning in the hedonic consumption. European Journal of marketing, v.33, n. 3/4, p. 273-290, 1999.

JACOBI, P. Meio ambiente urbano e sustentabilidade: alguns elementos para a reflexão. In: CAVALCANTI, C. (Org.). Meio ambiente, desenvolvimento sustentável e políticas públicas. São Paulo: Cortez, 1997.

KÖCHE, J.C. Fundamentos de metodologia científica: teoria da ciência e iniciação à pesquisa. 14.ed. Rio de Janeiro.Vozes, 1997.

LONGENECKER, Justin, G. Introdução a administração: uma abordagem comportamental. São Paulo: Atlas, 1981.

MALHOTRA, N. Pesquisa de marketing: uma orientação aplicada. Porto Alegre: Bookman, 2006

MILHEIRO, E.; LIMA, V. O Ordenamento Turístico em Áreas Protegidas e os Sistemas de Informação Geográfica, Comunicação apresentada no $12^{\circ}$ Congresso da APDR, 15-17 de Setembro de 2006, Viseu.

NAHAS. M.V. Atividade física, saúde e qualidade de vida: conceitos e sugestões para um estilo de vida ativa. 4.ed. Londrina: Midiograf, 2006.

ORGANIZAÇÃO MUNDIAL DO TURISMO. Turismo, direção e redação Amparo Sancho: Tradução Dolores Maria Rodrigues Córner. São Paulo: Rocca, 2001.

PELEGRINNI FILHO, A. Ecologia, Cultura e Turismo. Campinas, Papirus, 2000, (Coleção Turismo).

PINE, J.; GILMORE, J.H. Satisfaction, sacrifice, surprise: three small steps create one giant leap into the expirience economy. Strategy and Leadership. p.. 18-23, 2000.

REFÚGIO Ecológico Pedra Afiada. Disponível em: <http://www.pedraafiada.com.br>. Acesso em: 25 fevereiro 2014.

RELATÓRIO de Brundcthland. Nosso futuro comum. 1991. Disponível em: $<$ http://wwww.futurocomum.spruz.com./downloads.htm>. Acesso em: 25 fevereiro 2014.

RODRIGUES, A.B. Turismo rural no Brasil: ensaio de uma tipologia. In: ALMEIDA, J.A.; FROELICH, J.M.; RIEDL, M. (orgs). Turismo rural e desenvolvimento sustentável. Campinas, SP: Papirus, 2000.(Coleção Turismo).

ROQUE. A.M.; MENDONÇA, M.C.A. Bases para a produção do turismo no espaço rural. CONGRESSO BRASILEIRO DE TURISMO RURAL. 1999, Piracicaba, SP. Anais... Piracicaba: FEALQ, 1999.

RUSCHMANN, D. Turismo no Brasil: Análise e Tendências. Barueri: Manole Ltda. 2002.

SCHENINI, P.C. Gestão empresarial sustentável. In: SCHENINI, P.C. Gestão empresarial sócio ambiental. Florianópolis: UFSC, 2005. 184 p.

SCHIFFMAN, L.G.; KANUK, L.L. Consumer behavior. 6.ed. New Jersey: Prentice hall, Upper Saddle River, 1997.

SCHMITT, B.D. Marketing experimental. São Paulo: Nobel, 2002. 
SILVA, J.G.; VILARINHO, C.; DALE, PJ. Turismo em áreas rurais: suas possibilidades e limitações no Brasil. In: ALMEIDA, J.A.; FROELICH, J.M.; RIEDL, M. (orgs). Turismo rural e desenvolvimento sustentável. Campinas, SP: Papirus, 2000.(Coleção Turismo).

ZILLES, F.P. Se meu jipe falasse. A experiência de consumo dos usuários de veículos off Road. Dissertação de Mestrado. Porto Alegre. Universidade Federal do Rio Grande do Sul.

ZIMMERMMAN, A. Planejamento e organização do turismo rural no Brasil. In: ALMEIDA, J.A.; FROELICH, J.M.; RIEDL, M. (orgs). Turismo rural e desenvolvimento sustentável. Campinas, SP: Papirus, 2000.(Coleção Turismo).

Rafael Lima de Souza: Universidade de Caxias do Sul, Caxias do Sul, RS, Brasil. E-mail: rafael@giraomundo.com.br

Link para o currículo Lattes: http://lattes.cnpq.br/0808847528755555

Eurico de Oliveira Santos: Universidade de Caxias do Sul, Caxias do Sul, RS, Brasil.

E-mail: seurico58@terra.com.br

Link para o currículo Lattes: http://lattes.cnpq.br/7321278494223871

Maria Luiza Cardinale Baptista: Universidade de Caxias do Sul, Caxias do Sul, RS, Brasil.

E-mail: malu@pazza.com.br

Link para o currículo Lattes: http://lattes.cnpq.br/2996705711002245

Pedro de Alcântara Bittencourt César: Universidade de Caxias do Sul, Caxias do Sul, RS, Brasil.

E-mail: pacesar@ucs.br

Link para o currículo Lattes: http://lattes.cnpq.br/0900226519393513

Data de submissão: 28 de outubro de 2015

Data de recebimento de correções: 11 de novembro de 2016

Data do aceite: 11 de novembro de 2016

Avaliado anonimamente 